\title{
An Analysis of Strain Rate Distribution Using Streamline Model and A Quick Stop Device in Metal Cutting
}

\author{
Osama A. Kadhim ${ }^{1 *}$, Fathi A. Alshamma ${ }^{2}$
}

\section{Authors affiliations: \\ $1 *)$ M.Sc. Student, Mechanical \\ Engineering Dep., University of \\ Baghdad, Baghdad-Iraq. \\ osamaali2727@gmail.com}

2) Mechanical Engineering

Dep., University of Baghdad,

Baghdad-Iraq.

fathi alshamma@,coeng.uoba

ghdad.edu.iq

\section{Paper History:}

Received: $31^{\text {th }}$ May 2019

Revised: 9th June 2019

Accepted: 19 $9^{\text {th }}$ June 2019

\begin{abstract}
In this paper, a quick stop device technique and the streamline model were employed to study the chip formation in metal cutting. The behavior of chip deformation at the primary shear zone was described by this model. Orthogonal test of turning process over a workpiece of the 6061-T6 aluminum alloy at different cutting speeds was carried out. The results of the equivalent strain rate and cumulative plastic strain were used to describe the complexity of chip formation. Finite element analysis by ABAQUS/explicit package was also employed to verify the streamline model. Some behavior of formation and strain rate distribution differs from the experimental results, but the overall trend and maximum results are approximately close. In addition, the quick stop device technique is described in detail. Which could be used in other kinds of studies, such as the metallurgical observation.
\end{abstract}

Keywords: quick stop device, streamline model, chip formation, metal cutting, FEM.

\section{Introduction}

Metal machining is a nonlinear process with high shear strain, strain rate, and temperature. The plastic deformation is assumed to happen on a restricted zone, named the primary shear zone (PZL), as shown Fig.1. The shape of the zone limits the strain rate distribution. The evaluation of the strain rate appears as a crucial problem in metal cutting because it largely controls the material's thermoviscoplastic behavior [1].

Grid technique was generally used in literature as indirect experimental measurement by examining the grid distortion after deformation. the Direct measurement applications were also reported such as particle image velocimetry (PIV) used by Lee et al. (2006) [2] and digital image correlation (DIC) introduced by Hijazi and Madhavan (2008) [3]. However, these methods some of them are highly costed and others need typical and special setups and cutting condition to validate or it could go erroneously when applied to a traditional process in industrial practicing, that will have explained afterward in this paper.

Another method to analyze the flow of material in chip formation is by employing an analytic approach of flow lines to define the strain rate distribution. In this method, the velocity gradient and the strain rate distribution are directly obtained from the mathematical model of the streamline function $\psi$ [1]. In this study, Stream function is employed to experimentally investigate the material flow in orthogonal cutting validates by finite element analysis.

A typical metal cutting in form of continuous chip formation is commonly assumed homogenous laminar flow, but actually, this consideration is hard to achieve in industrial practice. Yeung et al. [4] proved this argumentative point, Fig. 2 shows streaklines of their results that evince a highly unsteady sinuous flow with significant turbulence. The streaklines are repeatedly folded, thus the entire chip forms by this behavior for all incoming material. This form has been erroneously represented in literature as homogenous flow.

Due to that in-homogeneity and sinuous flow phenomenon, it is difficult and could go erroneously to investigate and study the chip formation experimentally by traditional Visio-plasticity technique. Therefore, an alternative way will be introduced in this paper based on direct examination of chip's microstructure. This method is combined between the analytical approach of streamline model and by following the moving particles of the chip itself.

The studying of chip formation needs a device that rapidly stops the cutting process, allowing the chip to freeze as it has been during the formation process. Thus, a quick stop device (QSD) is used to rapidly decrease the relative speed between the cutting tool and the workpiece to zero then the frozen chip remains in contact with the workpiece. Thereafter the chip is extracted and prepared to be investigated [5]. Therefore, in designing a QSD some consideration points should be taken into account: the frozen chip should remain like it was before the device had been launched, the speed of device taking away for the workpiece is higher than cutting speed, a minimum separation of time, and controls the desirable time of stopping. In this paper, the quick stop device is designed and manufactured according to the approach of Azam and Ahmadloo [6].

NJES is an open access Journal with ISSN 2521-9154 and eISSN 2521-9162

This work is licensed under a Creative Commons Attribution-NonCommercial 4.0 International License 


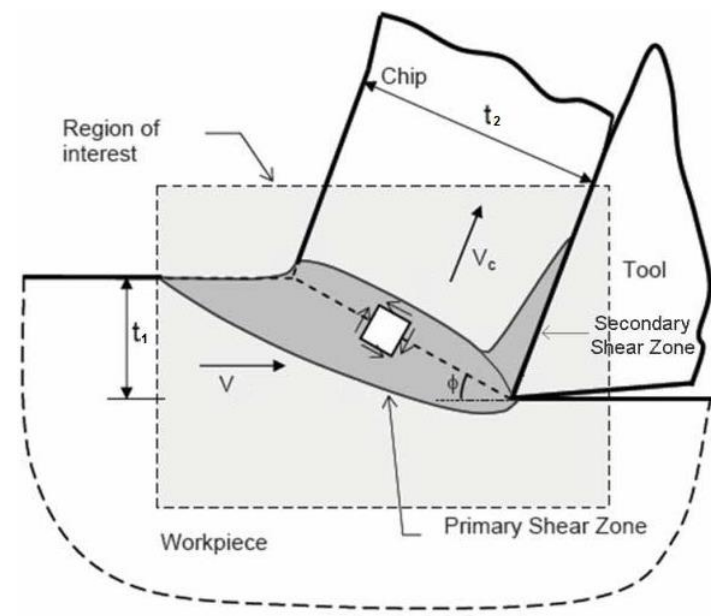

Figure (1): the primary and secondary shear zone of orthogonal metal cutting.

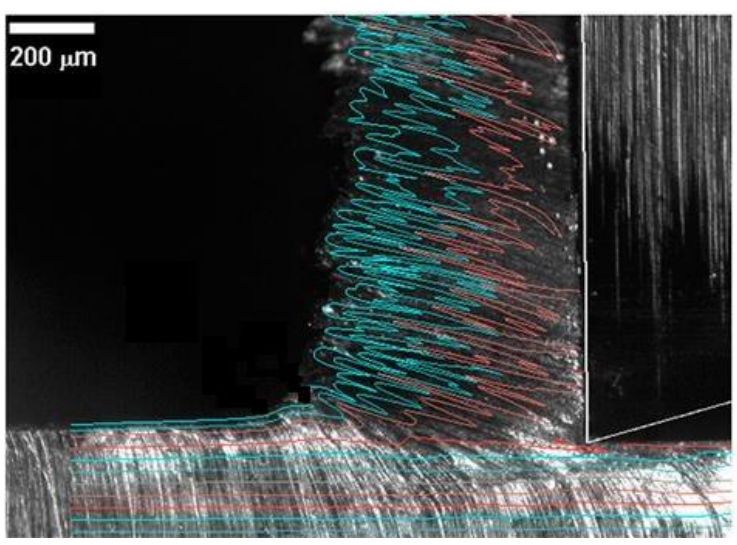

Figure (2): The streaklines of sinuous flow mode in metal

\section{Method and Material}

Dry machining turning test over a tube with different diameters are carried out. Employed material is 6061-T6 Aluminum machined with uncoated P15 DCMA110402 tool inserts which have a rake angle of zero and a clearness angle of +7 and SDJCR161611 tool holder. Testing was carried out with four different cutting speeds of 460, 408, 374 and $323 \mathrm{~mm} / \mathrm{s}$, with a cutting width and feed rate of two $(\mathrm{mm})$ and 0.2 $(\mathrm{mm} / \mathrm{rev})$ respectively. Set up and conditions above were considered to achieving orthogonal and plain strain configuration.

The design of QSD required to definite with some role and features to realize that it does functional purposes and does not hazard to human safety. Therefore, the QSD used in this study does not include any shear pin or explosives. In this mechanism, the cutting tool is driven away by two forces. First one is the force stored in the spring of the main toggle and the second one is by the ongoing force of workpiece upon cutting tool helped with the mainspring of mechanism. Consequently, the frozen chip is stuck with the workpiece. Fig .3 shows the manufactured QSD before and after activated. Fig .4 illustrates the components of mechanism

After the device is mounted into the tool post of the lathe and configured for the orthogonal test as can be seen in Fig.5, The aluminum workpiece was machined with the above-defined cutting condition. About three seconds later (to meet the study state) of chip removing the subsidiary lever was turned.

The frozen chip has been extracted as shown in Fig.6, then the samples were prepared for examination by these steps: (1) suspending in a resin, (2) grinding, (3) polishing and (4) etching with aluminum Keller's reagent $(2 \mathrm{ml} \mathrm{HF}, 3 \mathrm{ml} \mathrm{HCL}, 5 \mathrm{ml} \mathrm{HNO} 3$ and $190 \mathrm{ml}$ $\mathrm{H} 2 \mathrm{O})$ [7]. Then, an optical microscope was used to photographs the samples.
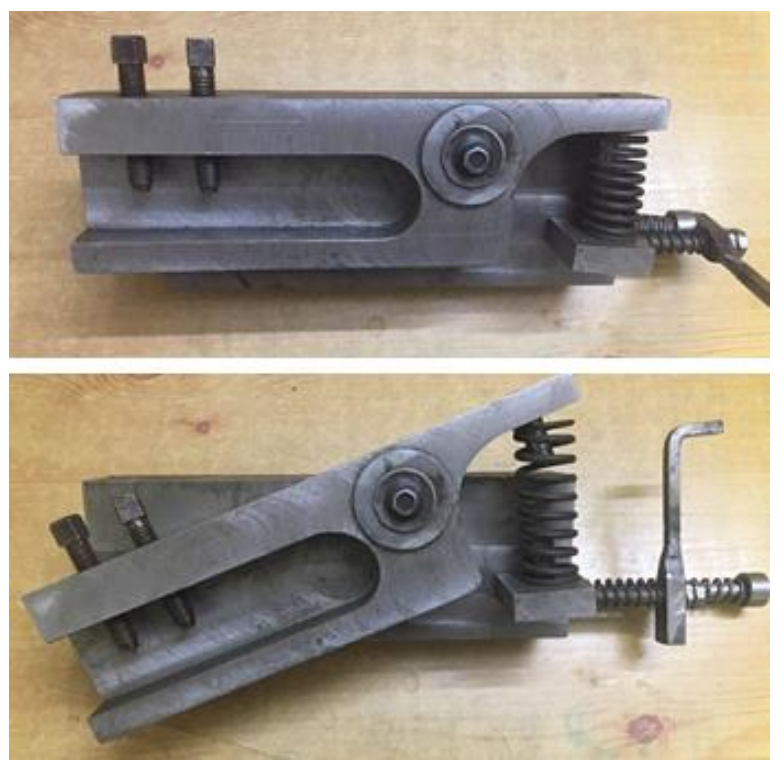

Figure (3): the manufactured quick stop device, before and after action.

\section{Streamline Model}

As mentioned before this model is employed to investigate the material flow, by using an analytical description to determine the strain rate distribution and the plastic strain. The flow line is mathematically described by the stream function $\boldsymbol{\psi}$ in Eq. (1) [8][1]:

$$
\psi(x, y)=\frac{1}{m}(y \cos \alpha+x \sin \alpha)^{n}+x^{n}=x_{0}^{n}
$$

where $\alpha$ is rake angle, $\mathrm{m}$ regards for the deviation of flow line in undeformed and deformed chip, the $\mathbf{n}$ parameter control the possible shapes of the flow lines, $\boldsymbol{x}_{\mathbf{0}}$ is the beginning positions of each flow line. $\boldsymbol{v}_{\boldsymbol{x}}$ and $\boldsymbol{v}_{\boldsymbol{y}}$ are the velocity gradient defined by the stream function as: 


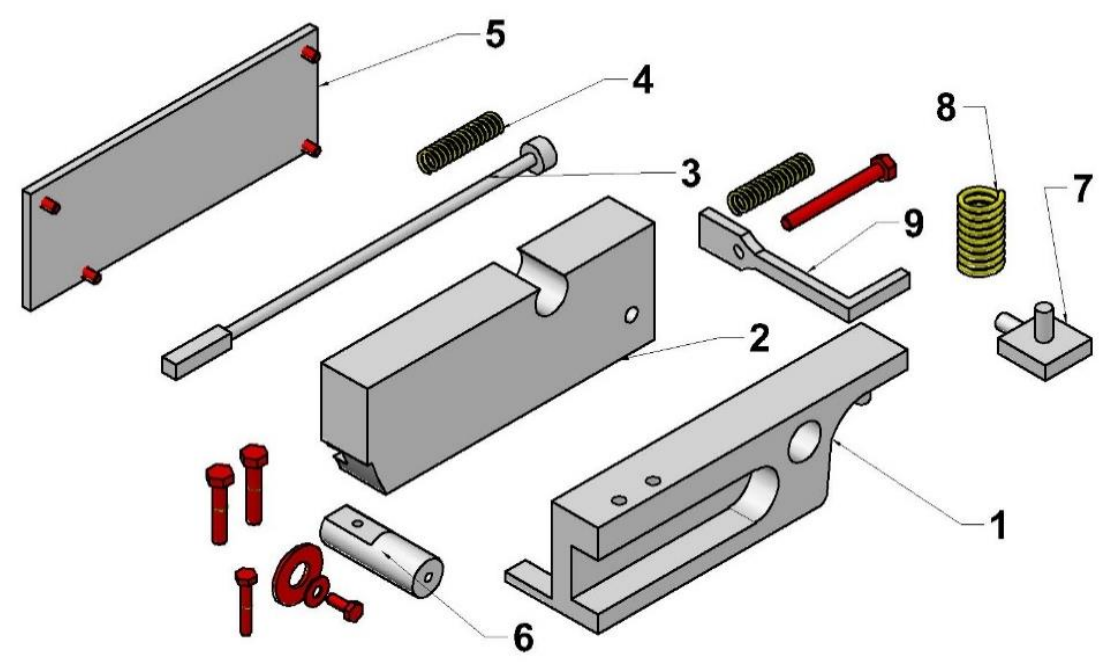

Figure (4): Assembly of the QSD: (1) householder, (2) body, (3) main toggle, (4) spring of toggle, (5) main toggle holder, (6) main pin, (7) spring stand, (8) the main spring of mechanism, (9) subsidiary lever

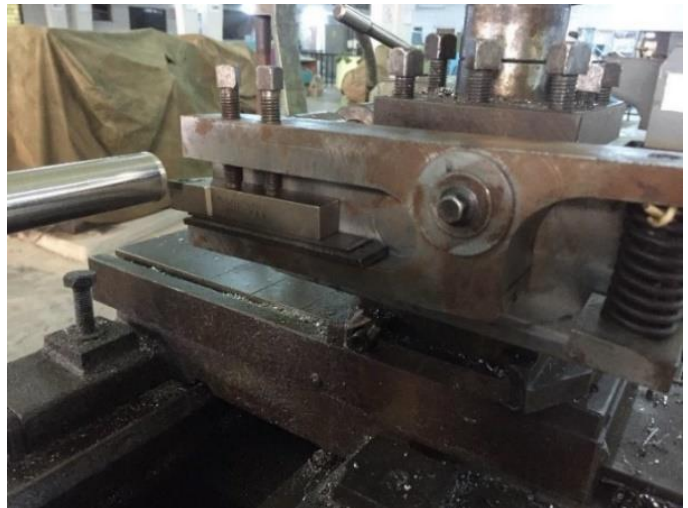

Figure (5): The QSD is mounted into the tool post of the lathe and configured for the orthogonal.

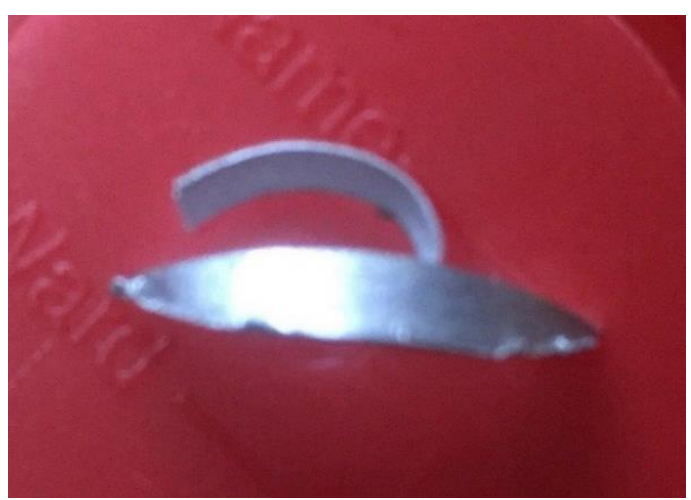

Figure (6): Frozen chip that extracted from the workpiece

$$
\begin{aligned}
v_{x}= & \lambda\left(n \cos \alpha(y \cos \alpha+x \sin \alpha)^{n-1} / m\right) \\
v_{y}= & -\lambda\left(n \cos \beta(y \sin \beta+x \cos \beta)^{n-1}\right. \\
& \left.+n \sin \alpha(y \cos \alpha+x \sin \alpha)^{n-1} / m\right)
\end{aligned}
$$

The incoming velocity $\boldsymbol{V}$ of the material determines the parameter $\lambda$ :

$$
v_{y}\left(x_{0}, y_{0}\right)=V
$$

From Eq. (2),(3) and(4) the $\boldsymbol{\lambda}$ is given in Eq.(5):

$$
\lambda=\frac{-V}{n x_{0}^{n-1}}
$$

plane strain can be considered when cutting width is relatively larger than cutting depth. The strain rate tensor for the plane strain can be expressed as follows:

$\dot{\varepsilon}_{y y}=\frac{\partial v_{y}}{\partial y}$

$\dot{\varepsilon}_{x x}=\frac{\partial v_{x}}{\partial x}$

$\dot{\varepsilon}_{x y}=\dot{\varepsilon}_{y x}=\frac{1}{2}\left(\frac{\partial v_{x}}{\partial y}+\frac{\partial v_{y}}{\partial x}\right)$

The equivalent strain rate in the sense of Von Mises is given by:

$\dot{\varepsilon}_{e q .}=\frac{2}{3} \sqrt{\frac{1}{2}\left(\left(\dot{\varepsilon}_{y y}-\varepsilon_{y y}\right)^{2}+\dot{\varepsilon}_{x x}^{2}+\dot{\varepsilon}_{y y}^{2}+3 \dot{\varepsilon}_{x y}^{2}\right)}$

When Eq. (9) integrated a long flow line, the cumulative plastic strain with $\boldsymbol{\alpha}=\mathbf{0}$ is given by [9]:

$$
\bar{\varepsilon}=\frac{2}{\sqrt{3}} \frac{\pi(n-1)}{n^{2} \sin (\pi / n)}
$$

the stream function $\boldsymbol{\psi}$ parameters in Eq. (1) was fitted using MATLAB. Firstly, the resulted frozen chips photos from the QSD is visually analyzed by proper tracing the flow formation of particle movement. Then, four flow lines nearest to tool tip was selected and a Cartesian coordinate $(\boldsymbol{\gamma}, \boldsymbol{x}, \boldsymbol{y})$ should be defined, where the $\boldsymbol{x}$ axis is supposed to be perpendicular to the cutting direction and $\boldsymbol{\gamma}$ is the angular position. thereafter, a nonlinear fitting program was implemented to find the streamline parameters according to the traced points of each line as seen in Fig. 7. 


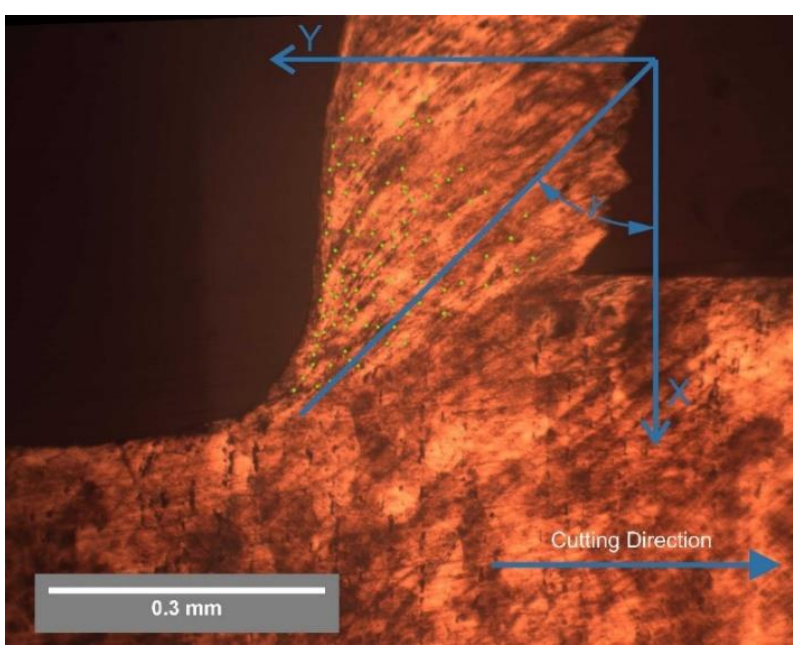

Figure (7): microscopic observation of the frozen chip with coordinate variables and traced points

\section{FEM}

ABAQUS/Explicit package for Finite Element Model (FEM) has been employed in order to simulate the cutting process. A 2D orthogonal model has been built for the estimation of strain and strain rate values. Fig. 8 shows the geometry of the model, built using square elements and Arbitrary Lagrangian-Eulerian (ALE) formulation step. Friction has been considered constant with a value of $=0.29$. The tool is considered as an elastic rigid body and the workpiece material follows a thermo-viscoplastic behavior described by the Johnson-Cook's law [10], with parameters calibrated by Dabboussi et al. [11] in order to represent the response of 6061-T6 Al, As bellow:

$$
\bar{\sigma}=\left(A_{J}+B_{J} \bar{\varepsilon}^{n_{J}}\right)\left(1+C_{J} \ln \left(\frac{\dot{\varepsilon}_{e f f}}{\dot{\varepsilon}_{0}}\right)\right)\left(1-\left(\frac{T-T_{0}}{T_{m}-T_{0}}\right)^{m_{J}}\right)
$$

Here $\overline{\boldsymbol{\sigma}}$ is the effective flow stress of the material, $\overline{\boldsymbol{\varepsilon}}$ is the cumulative plastic strain, $\dot{\boldsymbol{\varepsilon}}_{\boldsymbol{e f f}}$ the effective plastic strain rate, $\dot{\boldsymbol{\varepsilon}}_{\mathbf{0}}$ the reference plastic strain-rate of $1 \mathrm{~s}^{-1}, \boldsymbol{T}_{\mathbf{0}}$ the room temperature and $\boldsymbol{T}_{\boldsymbol{m}}$ the melting temperature. $\mathbf{A}_{\mathbf{J}}, \mathbf{B}_{\mathbf{J}}, \mathbf{n}_{\mathbf{J}}$ are the material constants for the strain hardening, $\mathbf{C}_{\mathbf{J}}$ is the constant for the strain rate dependence and $\mathbf{m}_{\mathbf{J}}$ is the thermal softening exponent. The values of the parameters are given in Table 1

Table (1): parameters of Johnson cook model

\begin{tabular}{|c|c|c|c|c|}
\hline $\begin{array}{c}\mathrm{A}_{\mathrm{J}} \\
(\mathrm{MPa})\end{array}$ & $\begin{array}{c}\mathrm{B}_{\mathrm{J}} \\
(\mathrm{MPa})\end{array}$ & $\mathrm{C}_{\mathrm{J}}$ & $\mathrm{n}_{\mathrm{J}}$ & $\mathrm{m}_{\mathrm{J}}$ \\
\hline 335 & 85 & 0.11 & 0.012 & 1 \\
\hline
\end{tabular}

A damage criterion was also applied to the element of workpiece by following the Johnson and Cook's damage law, the general expression for the strain at fracture is:

$$
\varepsilon_{f}=\left(D_{1}+D_{2} e^{\left(D_{3} \sigma *\right)}\right)\left(1+D_{4} \ln \varepsilon\right)\left(1+D_{5} T^{*}\right)
$$

where $\boldsymbol{\sigma}^{*}$ is the mean stress normalized by the effective stress, and $T^{*}$ is the homologous temperature. The parameters D1, D2, D3, D4, and D5 are material constants were obtained from B.M. Corbett [12] in Table 2.

Table (2): parameters of Johnson-cook damage model

\begin{tabular}{|c|c|c|c|c|}
\hline $\mathrm{D}_{1}$ & $\mathrm{D}_{2}$ & $\mathrm{D}_{3}$ & $\mathrm{D}_{4}$ & $\mathrm{D}_{5}$ \\
\hline-0.77 & 1.45 & -0.47 & 0 & 1.6 \\
\hline
\end{tabular}

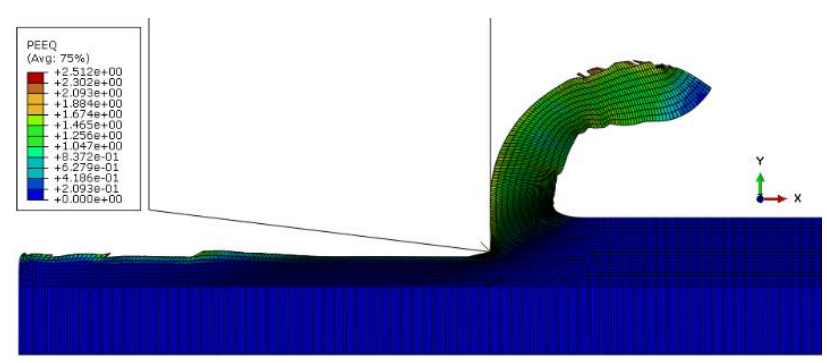

Figure (8): geometry of the FEM simulation

\section{Results}

The angular variable $\boldsymbol{\gamma}$ is introduced to clarify the position along the flow line. However, this variable is undependable to compare positions among different flow lines in this in-homogeneous chip formation study. It is only used to describe wideness of strain rate distribution along a flow line.

Fig. 9 describes the equivalent strain rate distribution in the sense of Von Mises on four selected flow lines for $V=459(\mathrm{~mm} / \mathrm{s})$. Strain rate begins with the value of zero at positions where the incoming velocity gradient still undeformed yet (the incoming velocity is hypothetically traced in this such this kind of observation study) until reaching a peak when entering the primary shear zone, then begins to recover again to zero when velocity is outgoing of the primary shear zone. Line A here is nearest to the tool tip (cutting edge). From D to A, strain rate distribution sharply increased as a maximum value and getting Narrower as a distribution wherever it is taking forward from tool tip to the free surface. This behavior confirms that the primary shear zone nearly a triangle in shape from tool tip to free surface. Besides, it is noteworthy to observe there is a variation in time to reach a zero value of strain rate again (velocity recovered to incoming value) for different lines in outgoing velocities that is may demonstrate the phenomenon of the chip curling. The maximum value of strain rate exceeds $3.57 \times 10^{4}$. However, it is probably higher when getting closer toward the tool tip.

The maximum equivalent strain rate distribution of four different velocities samples was obtained, as shown in Fig. 10 where the chosen flow line for each velocity is usually the closest one to the tool tip. The maximum value at $\mathrm{V}=459(\mathrm{~mm} / \mathrm{s})$ is equal to $3.57 \times 10^{4} s^{-1}$ then decline at $\mathrm{V}=408(\mathrm{~mm} / \mathrm{s})$ and 
Table (3): Summary of results

\begin{tabular}{|c|c|c|c|c|c|c|c|}
\hline & & & \multicolumn{3}{|c|}{ Maximum of } & $\dot{\boldsymbol{\varepsilon}}_{\text {eq.. }}\left(\boldsymbol{s}^{\mathbf{- 1}}\right)$ & \multicolumn{3}{|c|}{ Plastic strain $\overline{\boldsymbol{\varepsilon}}$} \\
\hline No. & $\mathrm{V}(\mathrm{mm} / \mathrm{s})$ & $\mathrm{t}_{2(\mathrm{~mm})}$ & Streamline & FEM & Streamline & FEM & classic \\
\hline 1 & 459 & 0.285 & $3.57 \times 10^{4}$ & $3.76 \times 10^{4}$ & 1.14 & 1.227 & 1.229 \\
\hline 2 & 408 & 0.295 & $2.94 \times 10^{4}$ & $3.24 \times 10^{4}$ & 1.133 & 1.176 & 1.241 \\
\hline 3 & 374 & 0.303 & $2.32 \times 10^{4}$ & $2.81 \times 10^{4}$ & 1.136 & 1.208 & 1.254 \\
\hline 4 & 323 & 0.31 & $2.35 \times 10^{4}$ & $2.75 \times 10^{4}$ & 1.137 & 1.152 & 1.266 \\
\hline
\end{tabular}

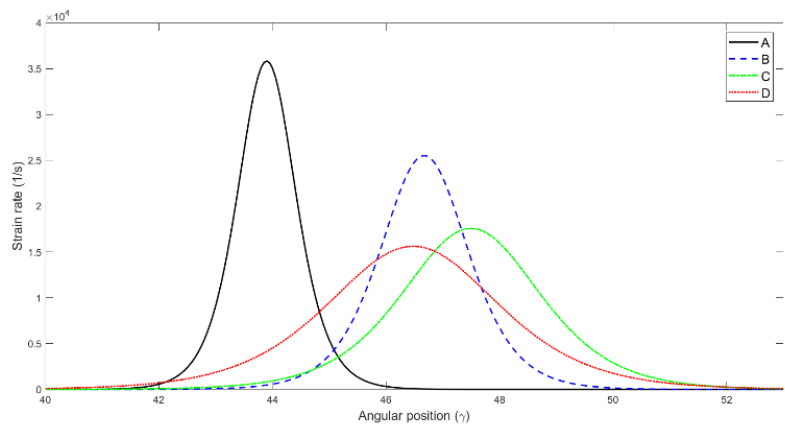

Figure (9): Equivalent strain rate at $V=459(\mathrm{~mm} / \mathrm{s})$

$\mathrm{V}=374(\mathrm{~mm} / \mathrm{s})$ which are equal to $2.94 \times 10^{4} \mathrm{~s}^{-1}$ and $2.32 \times 10^{4} \mathrm{~s}^{-1}$ respectively. At $\mathrm{V}=323(\mathrm{~mm} / \mathrm{s})$, the maximum strain rate slightly increased which is equal to $2.35 \times 10^{4} s^{-1}$, as detailed in Table 3. This may cause of a higher sever deformation at lower cutting speed. Although the range of chosen velocities is small, it seems convincingly sensitive more than other methods.

Fig. 11 illustrates the equivalent strain rate distribution at $\mathrm{V}=459(\mathrm{~mm} / \mathrm{s})$, obtained from the finite element model (FEM), analyzed at the same way of streamline model, as shown in Fig. 12. The predicted value of the maximum strain rate equal to $3.76 \times 10^{4} s^{-1}$ is close enough to that measured in the experiment. Additionally, the differences in the strain rate distribution and shape of formation from (A to D) is similar to that difference among those lines of streamline model. Nevertheless, two remarkable dissimilarities between streamline model and FEM was noticed. The first one: instead of steady growth and downfall of distribution curve in streamline model, trembling movement at these positions in FEM was happened. this might cause of attempting to simulate in-homogenous chip formation at FEM when was built, which is a good noticed point to consider that the two models are comparable. The second one: as shown in Fig. 13, approximately at $\gamma=70^{\circ}$; the trend trying to reach a peak again. This behavior due to the affection of secondary defamation zone causing the friction between tool rake face and chip surface. Besides, this behavior isn't evident in the streamline experiment model.

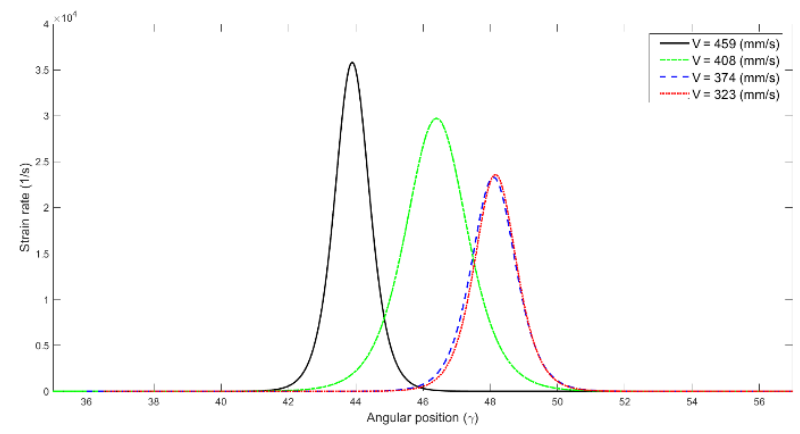

Figure (10): Equivalent strain rate at different cutting speed

Fig. 13 compared the strain rate distributing for each velocity between the two methods, the maximum values are close but the shape of the distribution and angular position wideness is different, this is denoting that the primary shear zone in simulation is much higher uniform than the experiment.

The cumulative plastic strain was studied with streamline model, FEM and a classical strain equation of shear plane theory, as follows in Eq. (12) and (13)

$$
\begin{aligned}
& \phi=\tan ^{-1}\left(\frac{\left(t_{1} / t_{2}\right) \cos \alpha}{1-\left(t_{1} / t_{2}\right) \sin \alpha}\right) \\
& \bar{\varepsilon}=\frac{1}{\sqrt{3}} \frac{\cos (\alpha)}{\sin (\phi) \cos (\phi-\alpha)}
\end{aligned}
$$

Where $\boldsymbol{\phi}$ is the shear angle.

First of all, to make the result of FEM applicable to compare, the values of plastic strain when reach the secondary shear zone were extracted, for the reason mention above and to focus on the primary share zone. As shown in Fig, 13 and 14, the data points refer to the beginning of entering the secondary shear zone which was marked at the starting rise of the second wave at around $\gamma=70^{\circ}$. The deformed chip thickness $\mathrm{t}_{2}$ for each velocity was observed, noticed that it decreases with higher velocity until it is equal to 2.85 $(\mathrm{mm})$ at $V=459(\mathrm{~mm} / \mathrm{s})$, which is may getting reached the undeformed chip thickness $\left(t_{1}=0.2 \mathrm{~mm}\right)$ at very higher cutting speed, that affects the calculation of the classical strain model in Eq. where the strain slightly decreases. as shown in Fig. 15. strains that calculated form streamline model is also slightly affected while the FEM model is the most sensitive to the variation of cutting speed. 


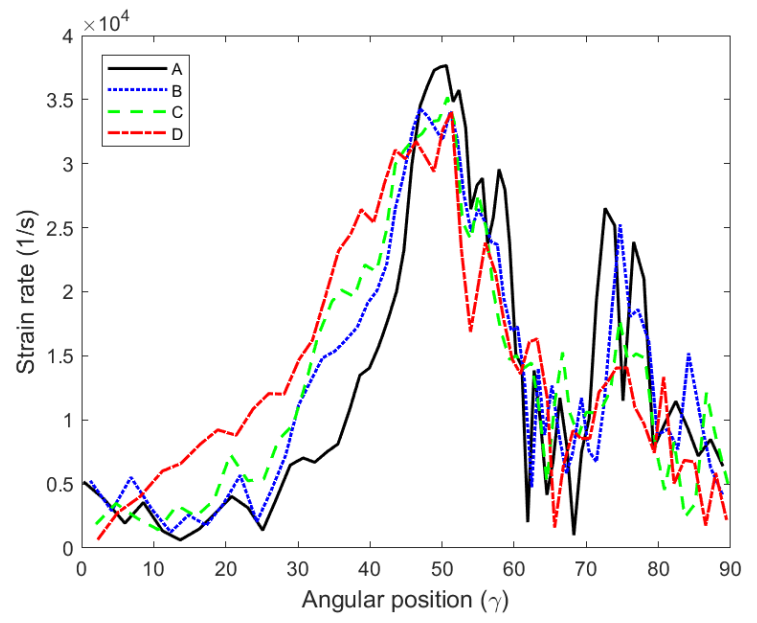

Figure (11): equivalent strain rate of FEM simulation at $\mathrm{V}=459(\mathrm{~mm} / \mathrm{s})$

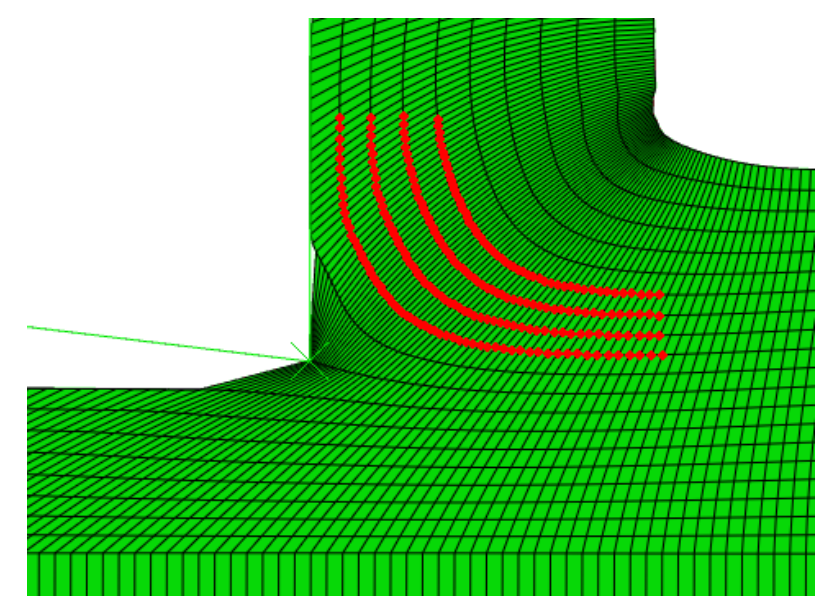

Figure (12); chosen area for analysis of the FEM simulation

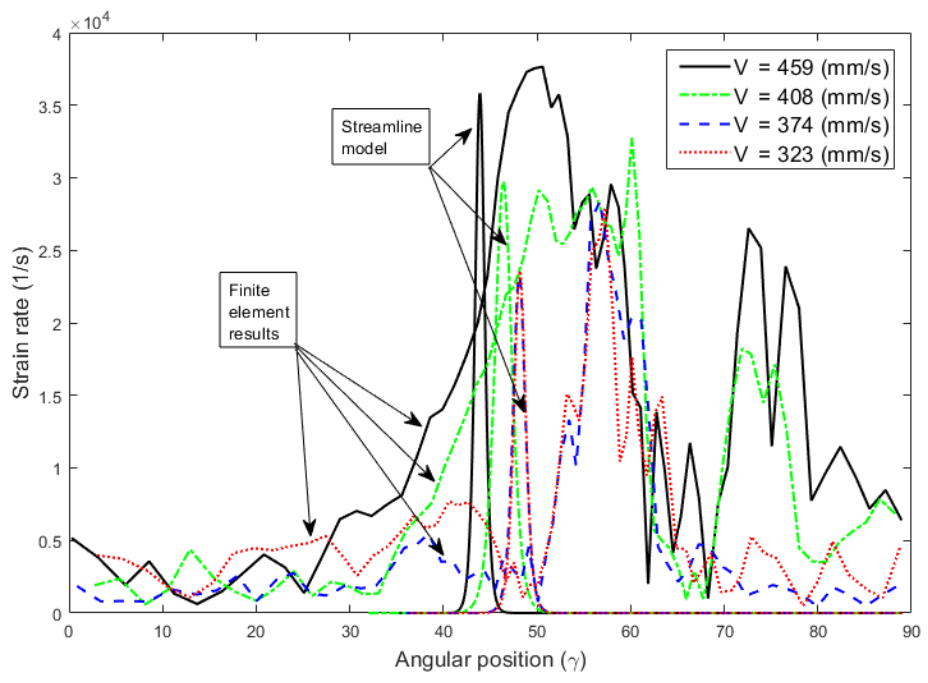

Figure (13): equivalent strain rate of FEM simulation and streamline model at different cutting speeds

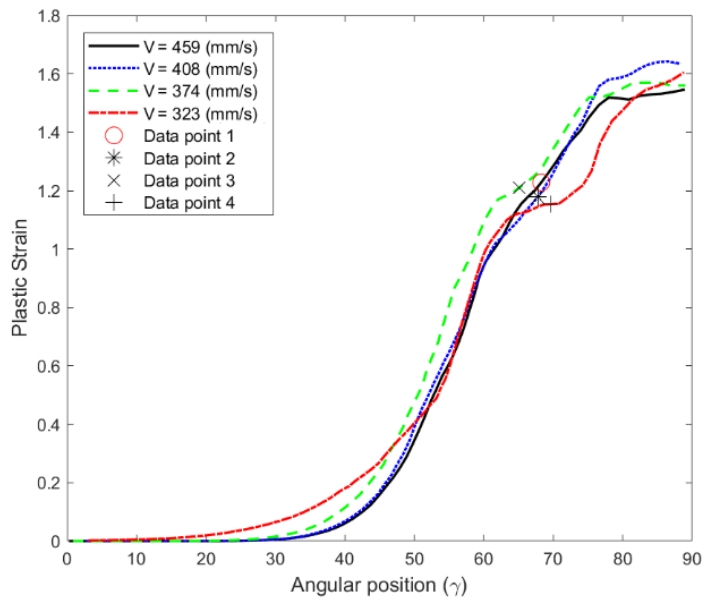

Figure (14): cumulative plastic strain of FEM simulation

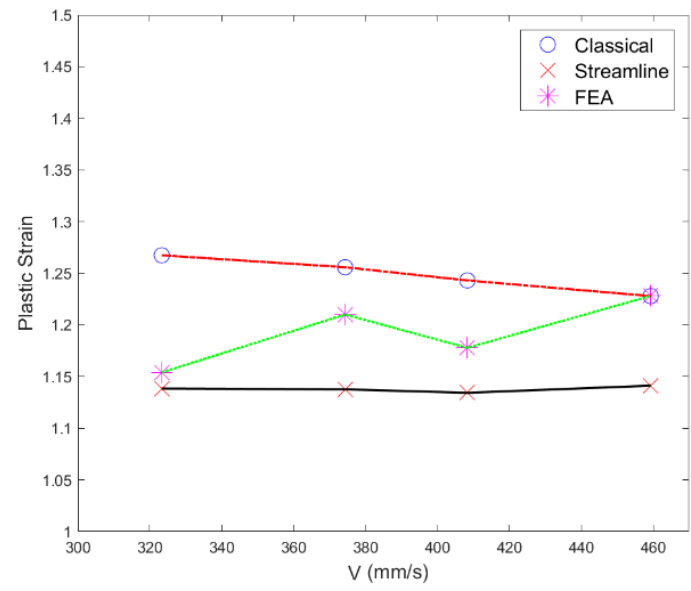

Figure (15): Maximum plastic strain calculated with tree different methods

\section{Conclusion}

A modified approach based on microscopic observation with the help of a quick stop device coupled with a streamline model was employed to 
study the in-homogenous chip formation in metal cutting. Orthogonal test of turning process for 6061 T6 aluminum alloy at different cutting speeds was used to study the strain rate distribution at the primary shear zone. The flow line parameters of stream function were found using nonlinear fitting program.

The equivalent strain rate and cumulative plastic strain were found using this model. The Complexity of chip formation was insightfully described using these results. Indicating that the maximum strain rate increasing notably toward the tool tip and the primary shear zone has a triangle shape. The effects of different cutting speed were also studied, showing that the equivalent strain rate generally increased with cutting speeds proportionally, except at lower cutting speed that slightly sever before increasing.

Finite element analysis by ABAQUS/explicit was also used to compare the results. Indicating that some behavior of formation and strain rate distribution differs from the experimental results due to the difference of approaches of analysis in these two models, but the overall trend and maximum results are approximately close. The range of error for the equivalent strain rate between finite element model and streamline model is $5.05 \%-17.43 \%$.

The cumulative plastic strain of streamline model is compared with the finite element model and the classical model, found that the simulation results is the most sensitive to the changing of the cutting speeds. The range of error for the plastic strain between finite element model and streamline model is 1.3\% - 7.09\%. While the range of error for the plastic strain between finite element model and streamline model is $7.24 \%$ $10.19 \%$.

In this approach, the overall results had successfully validated, which could use to compare with finite element and analytical results of chip formation.

Addition of the main objective in this paper, the quick stop device technique is described in details, which could use in other kinds of studies such as the metrological observation of the chip formation in the turning process.

\section{Recommendation for Future Work}

- Employing other materials for the workpiece such as: AA 2024-T3, Cu-ETP or steel AISI 1006

- Coupling the experiment measurement procedure of this paper with the algorithm and theories of digital image correlation (DIC) technique as a separate study, due to its complexity.

- Further developing in the streamline model to appends the analysis of the secondary shear zone.

\section{Refrencess}

[1] X. F. Bi, G. List, and Y. X. Liu, "Calculation of material flow in orthogonal cutting by using streamline model," in Key Engineering Materials, 2009, vol. 407, pp. 490-493.

[2] S. Lee, J. Hwang, M. Shankar, S. Chandrasekar, and W. Dale Compton, Large strain deformation field in machining, vol. 37. 2006.

[3] A. Hijazi and V. Madhavan, A novel ultra-high speed camera for digital image processing applications, vol. 19. 2008.

[4] H. Yeung, K. Viswanathan, W. D. Compton, and $\underline{\text { S. Chandrasekar, "Sinuous flow in metals," Proc. Natl. }}$ Acad. Sci., vol. 112, no. 32, pp. 9828-9832, 2015.

[5] O.A. Dahunsi and O. O. Awopetu, "The use of an indirect impact quick-stop mechanism during the turning of $\alpha$-titanium BT5 alloy," Int. J. Mach. Mach. Mater., vol. 3, no. 1-2, pp. 80-90, 2008.

[6] S. H. Mousavi Azam and E. Ahmadloo, "Analysis of Chip Removal Operations via

New Quick-Stop Device," Mater. Manuf. Process., vol. 31, no. 13, pp. 1782-1791, 2016.

[7] M. Bauccio and A. S. Metals, ASM Metals Reference Book, 3rd Edition. ASM International, 1993.

[8] G. List, G. Sutter, X. F. Bi, A. Molinari, and A. Bouthiche, "Strain, strain rate and velocity fields determination at very high cutting speed," J. Mater. Process. Technol., vol. 213, no. 5, pp. 693-699, 2013. [9] L.S. Tóth, R. A. Massion, L. Germain, S. C. Baik, and S. Suwas, "Analysis of texture evolution in equal channel angular extrusion of copper using a new flow field," Acta Mater., vol. 52, no. 7, pp. 1885-1898, 2004. [10] G. R. Johnson, "A constitutive model and data for materials subjected to large strains, high strain rates, and high temperatures," Proc. 7th Inf. Sympo. Ballist., pp. 541-547, 1983.

[11] W. Dabboussi and J. A. Nemes, "Modeling of ductile fracture using the dynamic punch test," Int. J. Mech. Sci., vol. 47, no. 8, pp. 1282-1299, 2005.

[12] B. M. Corbett, "Numerical simulations of target hole diameters for hypervelocity impacts into elevated and room temperature bumpers," Int. J. Impact Eng., vol. 33 , no. 1-12, pp. 431-440, 2006. 